\title{
Fitormônios e senescência pós-colheita do brócolos.
}

\author{
Lauricio Endres ${ }^{1, *}$; Fernando Luiz Finger ${ }^{2 /}$; Paulo Roberto Mosquim ${ }^{1 /}$ \\ ${ }^{1 /}$ UFV - Depo de Biologia Vegetal; ${ }^{2 /}$ Dep ${ }^{\text {to }}$ de Fitotecnia, 36570-000 Viçosa - MG.
}

\section{RESUMO}

Com o objetivo de avaliar os efeitos do ethephon e GA 3 sobre a degradação da clorofila, atividade de peroxidases e respiração durante a senescência pós-colheita do brócolos (Brassica oleracea $\mathrm{L}$. var. italica) cv. Piracicaba Precoce, suas inflorescências foram imersas logo após a colheita, durante uma hora, em 0,$1 ; 1,0 ; 10 ; 100$ e $1000 \mathrm{mg} . \mathrm{L}^{-1}$ de ethephon e, em um experimento paralelo, pulverizadas com 50, $250 \mathrm{e}$ $1000 \mathrm{mg} . \mathrm{L}^{-1} \mathrm{de} \mathrm{GA}_{3}$. O delineamento experimental utilizado foi inteiramente casualizado, com três repetições para a aplicação de ethephon e quatro repetições para a aplicação de $\mathrm{GA}_{3}$. As doses de 100 e 1000 mg. $\mathrm{L}^{-1}$ de ethephon tiveram efeito pronunciado sobre a degradação da colorofila, que foi mais evidente $48 \mathrm{~h}$ após a colheita, enquanto o tratamento controle ainda possuía $80 \%$ de seu teor inicial de clorofila. O tratamento de $1000 \mathrm{mg} . \mathrm{L}^{-1}$ de ethephon se destacou dos demais no aumento da atividade de peroxidases e da taxa respiratória a partir de $24 \mathrm{~h}$ após a colheita. $\mathrm{GA}_{3}$ não retardou a degradação da clorofila e não teve efeito sobre a taxa respiratória. No entanto, diminuiu a atividade de peroxidases em $25 \%, 38 \%$ e $43 \%$ nos tratamentos de 50, 250 e 1000 mg. $\mathrm{L}^{-1}$ de $\mathrm{GA}_{3}$, respectivamente, em relação ao controle, 48 horas após a colheita. Os resultados indicam que a atividade de peroxidases se mostrou muito sensível às alterações pós colheita do brócolos. No entanto, ainda é uma característica pouco utilizada nos estudos de pós-colheita. Finalmente, o brócolos possui uma taxa respiratória relativamente alta e rápida degradação da clorofila em sua vida pós-colheita, podendo responder ao etileno de fontes externas.

Palavras-chave: Brassica oleracea L. var italica, GA, ethephon, clorofila, peroxidases, taxa respiratória.

\section{ABSTRACT}

Fitohormones and postharvest senescence of broccoli.

To evaluate the effect of ethephon and $\mathrm{GA}_{3}$ on chlorophyll degradation, peroxidase activity and respiration during the postharvest senescence of broccoli (Brassica oleracea L. var. italica), harvested inflorescences of cv. Piracicaba Precoce were immersed, for one hour, in $0.1,1.0,10,100$ and $1000 \mathrm{mg} . \mathrm{L}^{-1}$ ethephon solutions. In a parallel assay, inflorescences were sprayed with 50, 250 and $1000 \mathrm{mg} . \mathrm{L}^{-1}$ of $\mathrm{GA}_{3}$. The experiments were set up in a complete randomized design, with three replications for ethephon application and four replications for $\mathrm{GA}_{3}$ application. The concentrations of 100 and $1000 \mathrm{mg} . \mathrm{L}^{-1}$ ethephon enhanced the rate of chlorophyll degradation, evident 48 hours after harvesting, while the control retained $80 \%$ of its initial chlorophyll content. Treatment with 1000 $\mathrm{mg} . \mathrm{L}^{-1}$ ethephon increased significantly peroxidase activity and respiration 24 hours after harvesting. $\mathrm{GA}_{3}$ did not affect the degradation of chlorophyll and respiration. However, it diminished the activity of peroxidases $25 \%, 38 \%$, and $43 \%$ for the treatments of 50,250 and $1000 \mathrm{mg} \cdot \mathrm{L}^{-1}$ of $\mathrm{GA}_{3}$, respectively, in relation to the control, 48 hours after harvesting. The results indicate that peroxidase activity was very sensitive to alterations after harvesting. However, this is still an infrequently used characteristic in postharvest studies. Finally, the broccoli possesses a relatively high respiration and a fast degradation rate of chlorophyll in its postharvest life, and is able to respond to ethylene from external sources.

Keywords: Brassica Oleracea L. var italica, $G A_{3}$, ethephon, chlorophyll, peroxidase, respiration.

\section{(Aceito para publicação em 07 de dezembro de 1998)}

$\mathrm{O}$ brócolos é altamente perecível após a colheita, com vida de prateleira de dois a três dias, quando não armazenado adequadamente, apresentando intenso amarelecimento (Yamauchi \& Watada, 1998). A coloração é o principal atributo de qualidade considerado pelos consumidores quando selecionam seus produtos vegetais (Barth et al., 1992) e é de fundamental importância quando consideramos os vegetais folhosos. Alguns estudos da conservação pós-colheita do brócolos têm sido feitos com a utilização de refrigeração (Makhlouf et al., 1989), atmosfera modificada (Ishikawa et al., 1998) e aplicação de fitormônios (Clarke et al., 1994).
A importância dos fitormônios na senescência tem sido mostrada pelo estudo da correlação entre os efeitos das aplicações e seus níveis endógenos com processos relacionados à senescência como, por exemplo, o teor de clorofila, atividade de peroxidases e respiração. Tem sido mostrado que o etileno promove a senescência foliar, enquanto giberelinas e citocininas a retardam (Yamauchi \& Watada, 1993; Han, 1995; Lers et al., 1998). Por exemplo, a aplicação de propileno (um análogo ao etileno) em brócolos, cv. Shogun, logo após a colheita, acelerou o amarelecimento e estimulou a atividade respiratória de suas inflorescências a partir de 24 horas após a colheita (Tian et al., 1994). Por outro lado, a aplicação pós-colheita de citocininas retardou o processo de amarelecimento do brócolos (Tian et al., 1995). Sabe-se que a aplicação de giberelinas retarda a senescência de folhas (Han, 1995; Lers et al., 1998), flores (Saks \& Staden, 1992) e frutos (Martínez et al., 1996; Biles et al., 1997). No entanto, até o momento, não há relatos demonstrando o efeito de giberelinas sobre a senescência pós-colheita do brócolos.

O objetivo desse trabalho foi estudar o efeito do ethephon e do ácido giberélico $\left(\mathrm{GA}_{3}\right)$ sobre a degradação da clorofila, atividade de peroxidases e taxa respiratória das inflorescências de brócolos armazenadas em temperatura ambiente.

*End. Corr : USP - IB - Depto de Botânica. Caixa Postal 11461. CEP 05422-970 São Paulo - SP E-mail: lendres@mail.ufv.br 


\section{MATERIAL E MÉTODOS}

Na condução do experimento foram utilizadas inflorescências de brócolos (Brassica oleracea L. var. italica), cv. Piracicaba Precoce, cultivadas na horta comercial da Universidade Federal de Viçosa, com todos os manejos culturais usuais até o ponto de colheita comercial (inflorescência totalmente desenvolvida, com as flores completamente fechadas). A colheita foi realizada entre 7 e 8 horas da manhã. No laboratório, as inflorescências, com 200 a $600 \mathrm{~g}$, foram imersas em solução $0,1 \%(\mathrm{v} / \mathrm{v}) \mathrm{de}$ hipoclorito de sódio durante quinze minutos e lavadas três a quatro vezes com água destilada. A aplicação de ethephon foi feita pela imersão das inflorescências, por uma hora, em solução nas concentrações: 0,$0 ; 0,1 ; 1,0 ; 10$; 100 e $1000 \mathrm{mg} . \mathrm{L}^{-1}$. Em seguida, as inflorescências foram acondicionadas em câmaras individualizadas por tratamento, no escuro, durante 72 horas. A temperatura de armazenamento foi de $25^{\circ} \mathrm{C} \pm 5^{\circ} \mathrm{C}$ e a renovação do ar da câmara foi feita com ar umedecido (95$97 \%$ UR) de modo a renovar completamente o ar da câmara a cada 30 min.

Em outro experimento foi feita a pulverização das inflorescências com 50 $\mathrm{ml}$ de solução por inflorescência de ácido giberélico, nas concentrações de 0 , 50,250 e $1000 \mathrm{mg} . \mathrm{L}^{-1}$ de $\mathrm{GA}_{3}$, contendo 1,0 g. $\mathrm{L}^{-1}$ de Tween 20. Após a pulverização, as inflorescências foram armazenadas, durante 96 horas em condições semelhantes à descritas anteriormente, com temperatura de $20^{\circ} \mathrm{C} \pm 2^{\circ} \mathrm{C}$. O delineamento experimental utilizado em ambos os experimentos foi inteiramente casualizado e a unidade experimental foi constituída de uma inflorescência de brócolos. Utilizou-se três repetições no experimento que avaliou os efeitos da aplicação de ethephon e quatro repetições no experimento com $\mathrm{GA}_{3}$. Foram calculados as médias e os desvios-padrão de cada tratamento.

Os teores de clorofila das inflorescências foram estimados 0,12 , 24,48 e 72 horas após a colheita e a atividade de peroxidases e a taxa respiratória foram medidas $0,6,12,24,48 \mathrm{e}$ 72 horas após a colheita. Nos tratamentos com $\mathrm{GA}_{3}$, foram feitas ainda mensurações 96 horas após a colheita. A quantificação dos teores de clorofila foi feita pelo método de Arnon (1949). A atividade de peroxidases foi quantificada pelo método descrito por Lagrimini \& Rothstein (1987). O teor de proteína do extrato enzimático foi estimado pelo método de Bradford (Bradford, 1976), tomando-se BSA como padrão. A produção de $\mathrm{CO}_{2}$ das inflorescências foi determinada em um analisador de gás no infravermelho (IRGA), marca ADC, modelo LCA-4, onde cerca de $15 \mathrm{~g}$ da inflorescência foram colocados em uma câmara de $1,5 \mathrm{~L}$, com um fluxo de ar de 36L.h ${ }^{-1}$. As inflorescências foram aclimatadas à temperatura de $20^{\circ} \mathrm{C}$ por 30 minutos, antes da determinação da produção de $\mathrm{CO}_{2}$.

\section{RESULTADOS E DISCUSSÃO}

As alterações do conteúdo de clorofila do brócolos foram mínimas nas primeiras 24 horas após a colheita, ocorrendo, após, uma drástica queda durante o período de armazenamento (Figura 1a), atingindo $20 \%$ do conteúdo inicial no tratamento controle, após 72 horas de armazenamento. Comportamento similar pôde ser observado em folhas destacadas de pepino (Lewington \& Simon, 1969) e discos de folhas de aveia (Thimann et al., 1977). Os tratamentos onde foram aplicados 100 e $1000 \mathrm{mg} . \mathrm{L}$ ${ }^{1}$ de ethephon tiveram efeito mais intenso na indução da degradação da clorofila do brócolos, sendo evidente 48 horas após a colheita, quando as inflorescência não tratadas (controle) possuíam 80\% do conteúdo inicial de clorofila, enquanto as inflorescências tratadas com $100 \mathrm{e}$ $1000 \mathrm{mg} . \mathrm{L}^{-1}$ de ethephon somente possuíam $35 \%$ e $25 \%$ de seu teor inicial de clorofila, respectivamente. Essa diferença diminuiu 72 horas após a colheita, provavelmente devido ao estado avançado de senescência do tecido. A coloração é usada como indicativo do avanço da senescência do brócolos, que perde totalmente sua coloração verde em dois ou três dias a $20^{\circ} \mathrm{C}$ (King \& Morris, 1994b). O amarelecimento de vegetais folhosos ocorre devido à degradação da clorofila e pode ser catalisado por peroxidases quando na presença de compostos fenólicos (Huff, 1982).
Isoenzimas de peroxidase são encontradas no interior dos cloroplastos, que na presença de compostos fenólicos, catalisam a reação de degradação da clorofila (Yamauchi \& Watada, 1991).

Observou-se, 6 horas após a colheita, (Figura 1b) que houve um ligeiro aumento na atividade de peroxidases em todos os tratamentos, possivelmente devido ao estresse da colheita. Muitas espécies respondem ao estresse pelo aumento da síntese de certas enzimas antioxidantes, como é o caso das peroxidases (Simon \& Ross, 1970; Espelie et al., 1986). Ainda, observouse que a partir de 12 horas após a colheita (Figura 1b) em todos os tratamentos com ethephon houve um segundo aumento da atividade de peroxidases, enquanto nas inflorescências não tratadas com ethephon essa elevação ocorreu somente a partir de 24 horas após a colheita, sugerindo que o ethephon, em todas as concentrações, acelerou a senescência do tecido. No entanto, a partir de 24 horas após a colheita, somente o tratamento de $1000 \mathrm{mg} . \mathrm{L}^{-1}$ de ethephon se destacou dos demais na indução da atividade de peroxidases. Observa-se na figura la e $1 \mathrm{~b}$ uma correlação inversa entre o teor de clorofila e atividade de peroxidases, a partir de 24 horas após a colheita, sugerindo que o etileno elevou o estado oxidativo do tecido e, como em folhas de espinafre (Yamauchi \& Watada, 1991), que as peroxidases foram as responsáveis pela degradação das clorofilas.

A taxa respiratória caiu drasticamente em todos os tratamentos durante as primeiras 12 horas após a colheita (Figura 1c). Resultados similares foram obtidos por Rushing (1990), que observou declínio da respiração do brócolos, cv. Citation, até 24 horas após a colheita, a $16^{\circ} \mathrm{C}$ e King \& Morris (1994a), que observaram que a respiração de três cultivares de brócolos diminuia até 12 horas após a colheita, quando armazenados a $20^{\circ} \mathrm{C}$. O declínio da taxa respiratória após a colheita tem sido descrito em órgãos vegetativos (King et al., 1990) e em flores (Trippi \& Paulin, 1984) e pode estar associado à exaustão de substratos respiratórios prontamente acessíveis, como os carboidratos solúveis, por exemplo (King \& Morris, 
1994a). A partir de 12 horas após a colheita, comparado ao comportamento da atividade de peroxidases (Figura 1b), somente o tratamento de $1000 \mathrm{mg} . \mathrm{L}^{-1} \mathrm{de}$ ethephon se destacou dos demais na indução da taxa respiratória (Figura 1c), possivelmente refletindo o elevado estado oxidativo do tecido, ocasionado pela presença do etileno liberado pelo ethephon.

A aplicação de $\mathrm{GA}_{3}$ não retardou a degradação da clorofila (Figura 2a) e não teve efeito sobre a taxa respiratória das inflorescências do brócolos (Figura 2c). No entanto, a aplicação de $\mathrm{GA}_{3}$ retardou a senescência de flores de cravo (Saks \& Staden, 1993) e o amarelecimento de folhas de alface (Aharoni et al., 1975) e salsa (Lers et al., 1998). Por outro lado, em todos os tratamentos com GA $\mathrm{G}_{3}$, observou-se uma redução da atividade das peroxidases a partir de 12 horas após a colheita, em relação ao controle (Figura 2b). Quarenta e oito horas após a colheita, por exemplo, a atividade das peroxidases diminuiu cerca de $25 \%$ para o tratamento de $50 \mathrm{mg} . \mathrm{L}^{-1} \mathrm{de} \mathrm{GA}, 38 \%$ para $250 \mathrm{mg} . \mathrm{L}^{-1}$ de $\mathrm{GA}_{3}$ e $40 \%$ para $1000 \mathrm{mg} . \mathrm{L}^{-1} \mathrm{de}^{\mathrm{GA}}$ em relação ao controle. Esses resultados sugerem, como em pétalas de rosas, onde o $\mathrm{GA}_{3}$ diminuiu a fluidez e a permeabilidade das membranas (Sabehat \& Zieslin, 1994), uma menor oxidação dos tecidos e, consequentemente, menor produção de hidroperóxidos. A atividade de peroxidases se mostrou bastante sensível a alterações fisiológicas pós-colheita de brócolos, podendo responder a estresses quando ainda não são observados por outras características como, por exemplo, o teor de clorofila e a taxa respiratória.

A senescência pós-colheita do brócolos é bastante rápida. Por isso a associação de técnicas de conservação pós-colheita se tornam necessárias para obtermos resultados mais expressivos como, por exemplo, o uso de reguladores de crescimento associado à refrigeração e/ou atmosfera modificada, como observado por Lers et al. (1998) na conservação pós-colheita de salsa. No entanto, essa hipótese ainda deve ser testada. O brócolos possui uma alta taxa respiratória e ao mesmo tempo possui

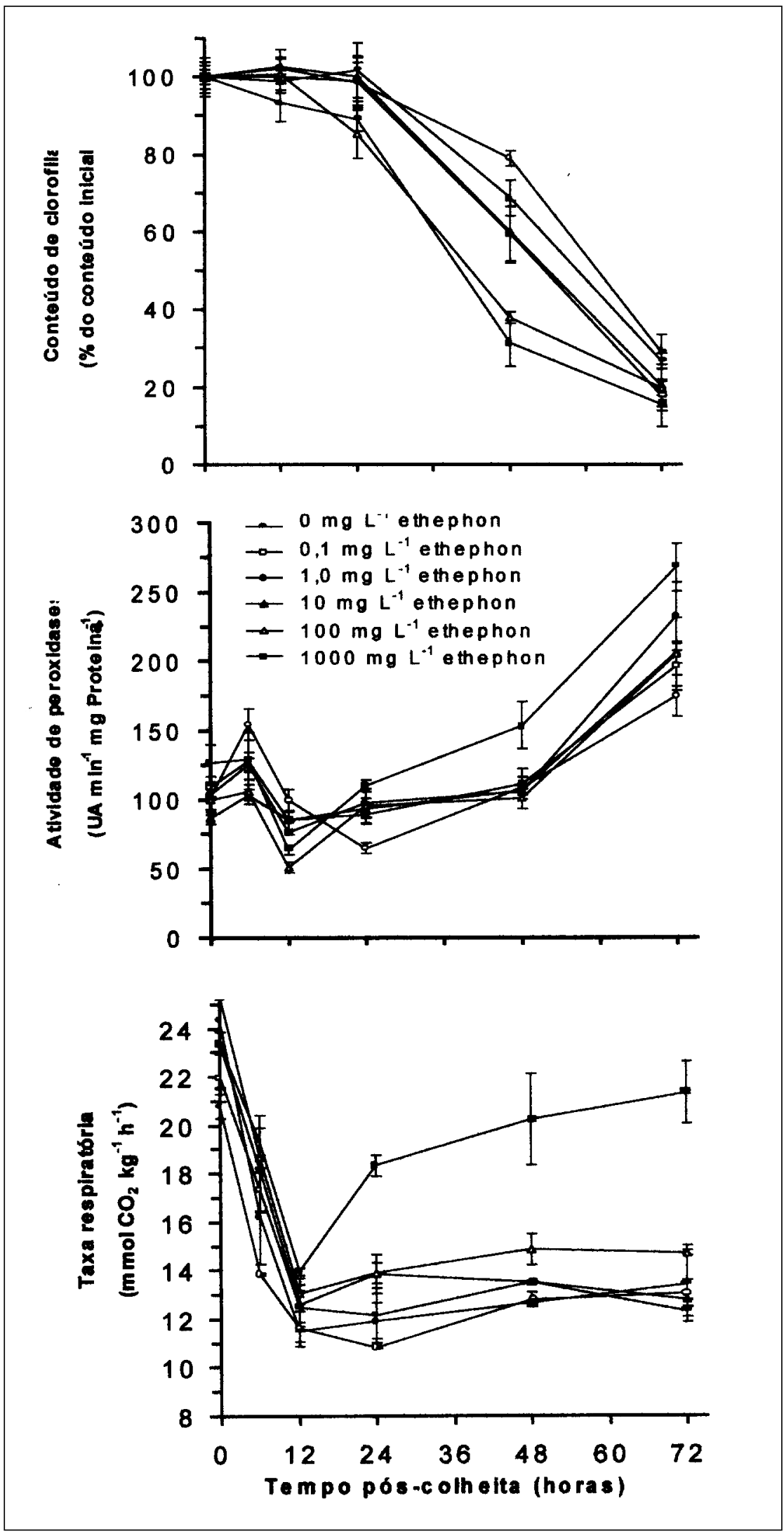

Figura 1. Teor de clorofila (A), atividade de peroxidases (B) e taxa respiratória (C) de inflorescências de brócolos imersas em solução de ethephon durante uma hora e armazenadas a $25^{\circ} \mathrm{C} \pm 5^{\circ} \mathrm{C}$, a $95-97 \%$ UR, no escuro. Barras verticais indicam o desvio-padrão. Viçosa, UFV, 1995. 

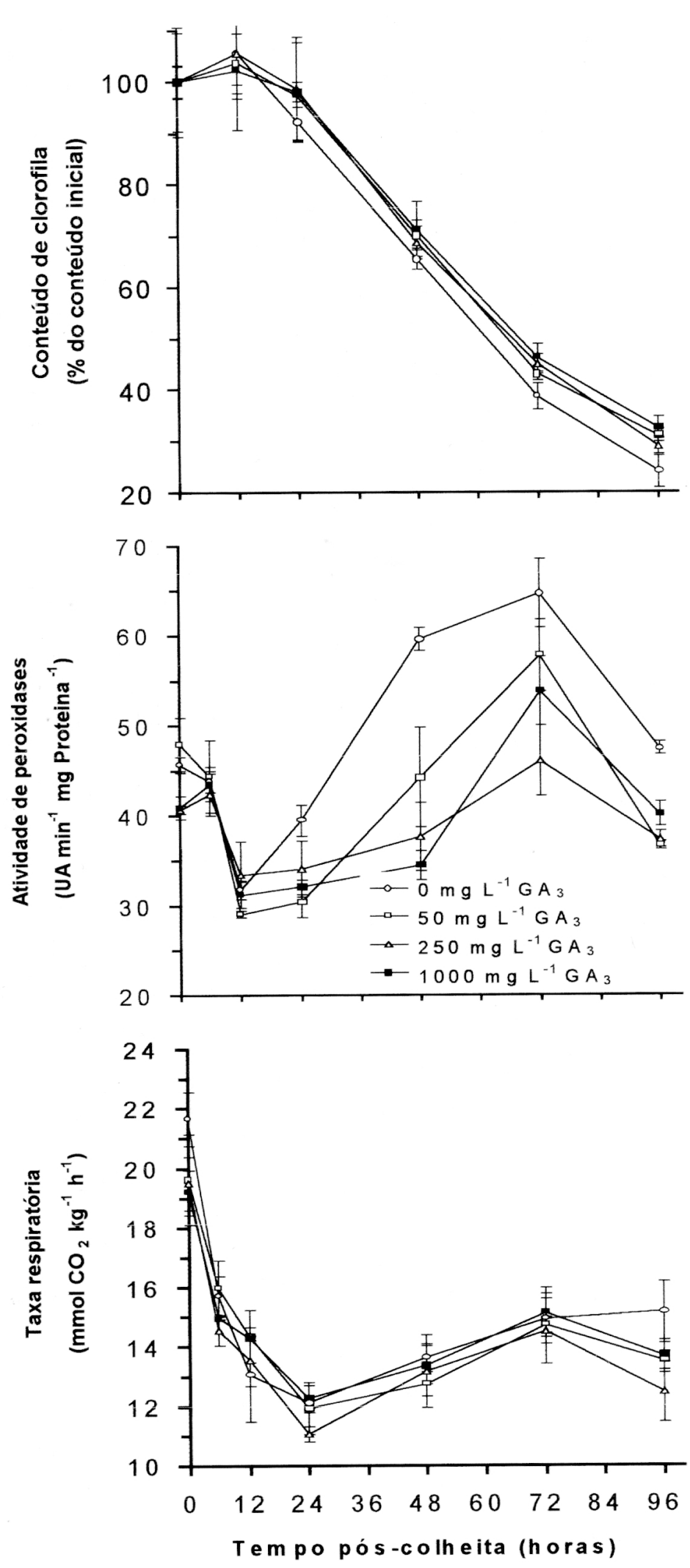

Figura 2. Teor de clorofila (A), atividade de peroxidases (B) e taxa respiratória (C) de inflorescências de brócolos pulverizadas após a colheita com solução de $\mathrm{GA}_{3}$ e armazenadas a $20 \mathrm{oC} \pm 20 \mathrm{C}$, a $95-97 \%$ UR, no escuro. Barras verticais indicam o desvio-padrão. Viçosa, UFV, 1995. baixas reservas de carboidratos (King \& Morris, 1994b). A manutenção da respiração de produtos hortícolas após a colheita é importante para a manutenção da homeostase metabólica de seu tecido. Assim sendo, a imersão da haste floral em solução de sacarose (Goldthwaite, 1974) pode vir a ser uma boa técnica na conservação pós-colheita do brócolos, merecendo estudos mais detalhados. Finalmente, deve-se evitar armazenar o brócolos, em um mesmo ambiente, com outros produtos de origem vegetal que possuem alta produção de etileno, principalmente a partir de 24 horas após a colheita, quando sua inflorescência parece estar mais sensível a esse fitormônio.

\section{LITERATURA CITADA}

AHARONI, N.; BACK, A.; BEN-YHOSHUA, S.; RICHMOND, A.E. Exogenous gibberellic acid and the cytokinin isopentenyladenine retardants of senescence in romaine lettuce. Journal of American Society for Horticultural Science, v. 100, p. 4 - 6, 1975.

ARNON, D.I. Copper enzyme in isolated chloroplasts. Polyphenoloxidase in Beta vulgaris. Plant Physiology, v. 24, p. 411 416, 1949.

BARTH, M.M.; PERRY, A.K.; SCHMIDT, S.J.; KLEIN, B.P. Misting affects market quality and enzyme activity of broccoli during retail storage. Journal of Food Science, v. 57, p. 954 - 957, 1992.

BILES, C.L.; KUEHN, G.D.; WALL, M.M.; BRUTON, B.D.; WANN, V. Characterisation of chili pepper fruit peroxidases during ripening. Plant Physiology and Biochemistry, v. 35, p. 273 270, 1997.

BRADFORD, M.M. A rapid and sensitive method for the quantification of microgram quantities of protein utilising the principle of protein-dye binding. Analitic Biochemistry, v. 72, p. 248 - 254, 1976.

CLARKE, S.F.; JAMESON, P.E.; DOWNS, C. The influence of 6-benzylaminopurine on post-harvest senescence of floral tissues of broccoli (Brassica oleracea var Italica). Plant Growth Regulation, v. 14, p. 21 - 27, 1994.

ESPELIE, K.E.; FRANCESCHI, V.R.; KOLATTUKUDY, P.E. Immunocytochemical localisation and time course of appearance of an anionic peroxidase associated with suberization in woundhealing potato tuber tissue. Plant Physiology, v. 81, p. 487 - 492, 1986.

GOLDTHWAITE, J. Energy metabolism of Rumex leaf tissue in the presence of senescence-regulating hormones and sucrose. Plant Physiology, v. 54, p. 399 - 403, 1974. 
HAN, S.S. Growth regulators delay foliar chlorosis of easter lily leaves. Journal of American Society for Horticultural Science, v. 120 , p. $254-258,1995$.

HUFF, A. Peroxidase-catalysed oxidation of chlorophyll by hydrogen peroxide. Phytochemistry, v. 21, p. 261 - 265, 1982.

ISHIKAWA, Y;; WESSLING, C.; HIRATA, T; HASEGAWA, Y. Optimum broccoli packaging conditions to preserve glutathione, ascorbic acid, and pigments. Journal of the Japanese Society for Horticultural Science, v. 67 , p. 367 - 371, 1998

KING, GA.; WOOLLARD, D.C.; IRVING D.E. Physiological changes in asparagus spear tips after harvest. Physiologia Plantarum, v. 80, p. 393 - 400, 1990.

KING, G.A.; MORRIS, S.C. Physiological changes of broccoli during early postharvest senescence and through the preharvestpostarvest continuum. Journal of American Society for Horticultural Science, v. 119, p. 270 - 275, 1994a.

KING, G.A.; MORRIS, S.C. Early compositional changes during postharvest senescence of broccoli. Journal of American Society for Horticultural Science, v. 119, p. 1000 $1005,1994 \mathrm{~b}$.

LAGRIMINI, L.M.; ROTHSTEIN, S. Tissue specificity of tobacco peroxidase isozymes and their induction by wounding and tobacco mosaic virus infection. Plant Physiology, v. 84, p. 438 - 442, 1987.

LERS, A.; JIANG, W.B.; LOMANIEC, E.; AHARONI, N. Gibberellic acid and $\mathrm{CO}_{2}$ additive effect in retarding postharvest senescence of parsley. Journal of Food Science, v. 63, p. 66 - 68, 1998.
LEWINGTON, R.J.; SIMON, E.W. The effect of light on the senescence of detached cucumber cotyledons. Journal of Experimental Botany, v. 20, p. 138 - 144, 1969.

MAKHLOUF, J.; CASTIAGNE, F.; ARUL, J. Long-term storage of broccoli under controlled atmosphere. HortScience, v. 24, p. $637-639,1989$.

MARTÍNEZ, G.A.; CHAVES, A.R.; AÑÓN, M.C. Effect of exogenous application of gibberellic acid on color change and phenylalanine ammonia-lyase, chlorophyllase, and peroxidase activities during ripening of strawberry fruit (Fragaria $X$ ananassa Duch.). Journal of Plant Growth Regulation, v. 15, p. 139 - 146, 1996.

RUSHING, J.W. Cytokinins affect respiration, ethylene production, and chlorophyll retention of packaged broccoli florets. HortScience, v. 25, p. 88 - 90, 1990.

SABEHAT, A.; ZIESLIN, N. GA 3 effects on postharvest alterations in cell membranes of rose (Rosa X Hybrida) petals. Journal of Plant Physiology, v. 144, p. 513 - 517, 1994.

SAKS, Y.; STADEN, J. van. The role of gibberellic acid in the senescence of carnation flowers. Journal of Plant Physiology, v. 139, p. 484 488, 1992.

SAKS, Y; STADEN, J. van. Evidence of the involvement of gibberellin in developmental phenomena associated with carnation flower senescence. Plant Growth Regulation, v. 12, p. $105-110,1993$.

SIMON, T.J.; ROSS, A.F. Enhanced peroxidase activity associated with induction of resistance to tobacco mosaic virus in hypersensitive tobacco. Phytopathology, v. 60 , p. 383 - 384, 1970
TIAN, M.S.; DAVIES, L.; DOWNS, C.G.; LIU, X.F.; LILL, R.E. Effects of floret maturity, cytokinin and ethylene on broccoli yellowing after harvest. Postharvest Biology and Technology, v. 6, p. 29 - 40, 1995.

TIAN, M.S.; DOWNS, C.G.; LILL, R.E.; KING, G.A. A role for ethylene in the yellowing of broccoli after harvest. Journal of American Society for Horticultural Science, v. 119, p. 276 - 281, 1994.

THIMANN, K.V.; TETLEY, R.M.; KRIVAK, B.M. Metabolism of oat leaves during senescence. V. Senescence in light. Plant Physiology, v. 59, p. 488 - 454, 1977.

TRIPPI, V.S.; PAULIN, M. The senescence of cut carnation, a phasic phenomenon. Physiologia Plantarum, v. 60, p. 221 - 226, 1984.

YAMAUCHI, N.; WATADA, A.E. Regulated chlorophyll degradation in spinach leaves during storage. Journal of American Society for Horticultural Science, v. 116, p. 58 - 62, 1991.

YAMAUCHI, N.; WATADA, A.E. Pigment changes in parsley leaves during storage in controlled or ethylene containing atmosphere. Journal of Food Science, v. 58, p. $616-618,1993$.

YAMAUCHI, N.; WATADA, A.E. Chlorophyll and xanthophyll changes in broccoli florets stored under elevated $\mathrm{CO}_{2}$ or ethylenecontaining atmosphere. HortScience, v. 31, p. $114-117,1998$. 